Topological Methods in Nonlinear Analysis

Volume 47, No. 1, 2016, 219-240

DOI: $10.12775 /$ TMNA. 2016.003

(C) 2016 Juliusz Schauder Centre for Nonlinear Studies

Nicolaus Copernicus University

\title{
MULTIPLE SOLUTIONS \\ FOR AN IMPULSIVE BOUNDARY VALUE PROBLEM ON THE HALF-LINE VIA MORSE THEORY
}

\author{
Karima Ait-Mahiout — Smail Djebali — Toufik Moussaoui
}

(Submitted by W. Kryszewski)

\begin{abstract}
This work is dedicated to Professor Lech Górniewicz on the occasion of Honoris Causa Doctorate granted to him by University of Zielona Góra
\end{abstract}

\begin{abstract}
In this paper, Morse theory is used to establish the existence of multiple solutions for an impulsive boundary value problem posed on the half-line.
\end{abstract}

\section{Introduction}

The aim of this paper is to study the following impulsive boundary value problem:

$$
\left\{\begin{array}{l}
-\left(p(t) u^{\prime}(t)\right)^{\prime}=q(t) f(t, u(t)), \quad t \neq t_{j}, j \in\{1,2, \ldots\}, t>0, \\
u(0)=u(+\infty)=0, \\
\Delta\left(p\left(t_{j}\right) u^{\prime}\left(t_{j}\right)\right)=h\left(t_{j}\right) I_{j}\left(u\left(t_{j}\right)\right), \quad j \in\{1,2, \ldots\},
\end{array}\right.
$$

where $f \in C^{1}([0,+\infty) \times \mathbb{R}, \mathbb{R}), 1 / p \in L^{1}((0,+\infty),(0,+\infty)), q \in L^{1}\left((0,+\infty), \mathbb{R}^{+}\right)$, $q>0$ almost everywhere, and such that

$$
M_{1}=\int_{0}^{+\infty}\left(\int_{t}^{+\infty} \frac{d s}{p(s)}\right) d t<\infty \quad \text { and } \quad M_{2}=\int_{0}^{+\infty} q(t)\left(\int_{t}^{+\infty} \frac{d s}{p(s)}\right) d t<\infty .
$$

2010 Mathematics Subject Classification. Primary: 34B37, 35A15; Secondary: 58E05, $58 \mathrm{E} 30$.

Key words and phrases. Impulsive boundary value problem; half-line; critical point; critical group; Morse theory. 
$I_{j} \in C^{1}(\mathbb{R}, \mathbb{R}), j=\{1,2, \ldots\}$ are the impulse functions and $t_{0}=0<t_{1}<\ldots<$ $t_{j}<\ldots<t_{m} \rightarrow+\infty$, as $m \rightarrow+\infty$, are infinite impulse points. We let

$$
\triangle\left(p\left(t_{j}\right) u^{\prime}\left(t_{j}\right)\right)=p\left(t_{j}^{+}\right) u^{\prime}\left(t_{j}^{+}\right)-p\left(t_{j}^{-}\right) u^{\prime}\left(t_{j}^{-}\right),
$$

where $u^{\prime}\left(t_{j}^{+}\right)=\lim _{t \rightarrow t_{j}} u^{\prime}(t)$ and $u^{\prime}\left(t_{j}^{-}\right)=\lim _{t \unlhd t_{j}} u^{\prime}(t)$ stand for the right and the left limits of $u^{\prime}$ at $t_{j}$, respectively. Finally, $h: \mathbb{R}^{+} \rightarrow \mathbb{R}$ is a function such that $\sum_{j=1}^{\infty}\left|h\left(t_{j}\right)\right|<\infty$.

Many problems modeling perturbed phenomena in nonlinear dynamics which are subject to jump discontinuities in velocity can be represented by impulsive boundary value problems (see, e.g., [3] and the references therein). In the last couple of years, various mathematical results based on topological methods (fixed point theorems, Leray-Schauder degree, ...) have been obtained in connection with such problems (see, e.g., [15]). Variational approaches have also been shown to be efficient tools in discussing the question of the solvability; we quote the minimization principle and the mountain pass theorem by Ambrosetti and Rabinowitz (as developed in [1], [2], [18]). Among works from the recent literature, we refer to [10] and also to the paper [8] which has discussed a problem with linear differential operator, a nonlocal condition at the origin, and a Neumann condition at positive infinity for a problem posed on the half-line. In [4], some existence results of a single solution are obtained for problem (1.1). The aim of this work is to investigate the existence of multiple solutions to problem (1.1). We first prove the existence of three distinct solutions, one of which is trivial, under sub-linear growth conditions upon the nonlinearity $f$. Our second existence result provides existence of infinitely many solutions under conditions including super-linear nonlinearities. Each existence result is illustrated by means of an example of application. The proofs of our main existence results are based on Morse theory. For this purpose, some basic notions and important results are recalled hereafter. For more details, we refer the reader to [5]-[7], [13], [14], [17].

Let $\mathcal{H}$ be a Hilbert space and $J \in C^{1}(\mathcal{H}, \mathbb{R})$ a functional. For a topological pair $(A, B)$, we denote by $H_{k}(A, B)$ the $k$-th singular relative homology group with coefficients in a ring $\mathbb{F}$ with characteristic zero (see [14]) and by $\beta_{k}=\operatorname{dim} H_{k}(A, B)$ the $k$-th Betti number. In algebraic topology, the $k$-th Betti number denotes the rank of the $k$-th homology group. Intuitively, the first Betti number of a space counts the maximum number of cuts that can be made without dividing the space into two pieces. Each Betti number is a natural number or $+\infty$. They are topological invariants. Finally $\beta_{k}(a, b)=\operatorname{dim} H_{k}\left(J^{b}, J^{a}\right)$ is the $k$-th Betti number with respect to the interval $(a, b)$.

Let $p$ be an isolated critical point of $J$, i.e., $J^{\prime}(p)=0$ and let $U$ be a neighbourhood of $p$ such that $J$ has only $p$ as a critical point in $U$. The critical groups 
of $J$ at $p$ are defined by

$$
C_{k}(J, p)=H_{k}\left(J^{c} \cap U, J^{c} \cap U \backslash\{p\}\right), \quad \text { for all } k \in \mathbb{N},
$$

where $J^{c}=\{u \in \mathcal{H}, J(u) \leq c\}$ is the $c$-sublevel set and $c=J(p) \in \mathbb{R}$. Let $K^{c}=\left\{u \in \mathcal{H}, J^{\prime}(u)=0, J(u)=c\right\}$ be the set of critical points at level $c$. In the case where $J^{\prime \prime}(p)$ exists with $p$ a critical point of $J$, the Morse index of $p$ is defined as the supremum of dimensions of the vector subspaces of $\mathcal{H}$ on which $J^{\prime \prime}(p)$ is negative definite (it can be equal to $\infty$ ) (see [7, Definition 5.1.12]). We say that $p$ is nondegenerate if the Hessian $J^{\prime \prime}(p)$ is invertible.

Definition 1.1. Let $J \in C^{1}(\mathcal{H}, \mathbb{R})$ and $c \in \mathbb{R}$. The functional $J$ satisfies the Palais-Smale condition at level $c$ (shortly $\mathrm{PS}_{c}$ ) if any sequence $\left(u_{n}\right)_{n \in \mathbb{N}} \subset \mathcal{H}$ such that

$$
J\left(u_{n}\right) \rightarrow c, \quad J^{\prime}\left(u_{n}\right) \rightarrow 0
$$

has a convergent subsequence. $J$ satisfies the Palais-Smale condition (PS in brief) if it satisfies the Palais-Smale condition at every level $c \in \mathbb{R}$.

Definition 1.2. Let $-\infty<a<b<+\infty$ be regular values and assume that $J$ has only isolated critical values $c_{1}<c_{2}<\ldots$ in $(a, b)$ with a finite number of critical points at each level and satisfies $\mathrm{PS}_{c}$, for all $c \in[a, b]$. Then the Morse type numbers of $J$ with respect to the interval $(a, b)$ are defined by

$$
M_{k}(a, b)=\sum_{i} \operatorname{dim} H_{k}\left(J^{a_{i+1}}, J^{a_{i}}\right) \quad(k \in \mathbb{N}),
$$

where $a=a_{1}<c_{1}<\ldots<c_{l}<a_{l}=b$. They are independent of the $a_{i}$ by the second deformation lemma and are related to the critical groups by the formula

$$
M_{k}(a, b)=\sum_{i=1}^{l} \sum_{u \in K^{c_{i}}} \operatorname{dim} C_{k}(J, u) \quad(k \in \mathbb{N}) .
$$

The following result will be crucial in proving the first existence result of the paper.

Lemma 1.3 ([7, Theorem 5.1.35]). Assume that $J \in C^{2}(\mathcal{H}, \mathbb{R})$ is bounded from below, satisfies the PS condition, and has a nondegenerate, non-minimum critical point $p$ with finite Morse index. Then $J$ has at least three distinct critical points.

Our second existence result is based on the following lemma.

Lemma 1.4 ([6, Theorem 4.3]). Assume that $J \in C^{1}(\mathcal{H}, \mathbb{R})$ satisfies the PS condition and let $a<b$ be two regular values of $J$. Suppose that $J$ has at most finitely many critical points on $J^{-1}[a, b]$ and the dimension of the critical group for every critical point is finite. Then the following inequality holds:

$$
M_{k}-M_{k-1}+\ldots+(-1)^{k} M_{0} \geq \beta_{k}-\beta_{k-1}+\ldots+(-1)^{k} \beta_{0}, \quad k=0,1, \ldots
$$


In addition

$$
\sum_{k=0}^{\infty}(-1)^{k} M_{k}=\sum_{k=0}^{\infty}(-1)^{k} \beta_{k}
$$

whenever the left-hand series of the equality converges.

However, in order to compute $M_{k}$ and $\beta_{k}$, some classical properties of the Leray-Schauder degree are required.

Lemma 1.5 ([7, Theorem 5.1.32]). Assume that $J \in C^{2}(\mathcal{H}, \mathbb{R})$ satisfies the PS condition, $J^{\prime}=I-A$, where $I$ is the identity operator, and $A: \mathcal{H} \rightarrow \mathcal{H}$ is compact. If $p$ is an isolated critical point of $J$, then there exists a neighbourhood $U$ of $p$ such that $p$ is the unique critical point of $J$ in $\bar{U}$ and

$$
\operatorname{deg}(I-A, U, \theta)=\sum_{k=0}^{\infty}(-1)^{k} \operatorname{dim} C_{k}(J, p),
$$

where $\operatorname{deg}(I-A, U, \theta)$ stands for the Leray-Schauder topological degree with respect to the zero element $\theta \in \mathcal{H}$.

REMARK 1.6. (a) The proof of Lemma 1.3 appeals to [7, Corollary 4.8.4] which only needs $J$ to be of $C^{1}$-class and also uses the additivity of EulerPoincaré characteristic which holds whenever the Morse index is defined, i.e. when $J^{\prime \prime}$ exists at $p$ (see the proof in [7, p. 343]). The condition that $J^{\prime \prime}(p)$ exists is then sufficient for application of Lemma 1.3.

(b) Lemma 1.5 equally holds when merely $J^{\prime \prime}(p)$ exists, a requirement for the Morse index to be defined (see the proof in [7, p. 341]).

The following result is known as Borsuk's theorem:

Lemma 1.7 [9, Theorem 9.4]. Let $X$ be a Banach space and $\Omega \subset X$ a symmetric bounded open set including $\theta$, the origin. If $K: \bar{\Omega} \rightarrow X$ is an odd compact map with $\theta \notin(I-K)(\partial \Omega)$, then the degree $\operatorname{deg}(I-K, \Omega, \theta)$ is odd.

The following technical lemma will be useful; it is classical in operator theory (see [19, Lemma 2]).

Lemma 1.8. Suppose that $X$ is a reflexive Banach space with dual space $X^{*}$ and $T \in \mathcal{L}\left(X, X^{*}\right)$ with $T^{*}=T$, where $\mathcal{L}\left(X, X^{*}\right)$ is the set of all continuous linear operators from $X$ to $X^{*}$ and $T^{*}$ is the dual operator of $T$. Assume that there exists a constant $C>0$ such that $\|T x\| \geq C\|x\|$, for all $x \in X$. Then $T^{-1}$ exists and $T^{-1} \in \mathcal{L}\left(X^{*}, X\right)$.

\section{Main existence results}

Consider the Hilbert space:

$$
H_{0, p}^{1}=\left\{u \in A C([0,+\infty), \mathbb{R}): u(0)=u(+\infty)=0, \sqrt{p} u^{\prime} \in L^{2}(0,+\infty)\right\}
$$


with the scalar product

$$
(u, v)=\int_{0}^{+\infty} p(t) u^{\prime}(t) v^{\prime}(t) d t+\int_{0}^{+\infty} u(t) v(t) d t
$$

and the corresponding norm (see Lemma 2.1):

$$
\|u\|_{H_{0, p}^{1}}=\sqrt{\int_{0}^{+\infty} p(t) u^{\prime}(t)^{2} d t+\int_{0}^{+\infty} u(t)^{2} d t .}
$$

Let the space $C_{0}=\left\{u \in C([0,+\infty), \mathbb{R}): \lim _{t \rightarrow+\infty} u(t)=0\right\}$ be endowed with the norm $\|u\|_{\infty}=\sup _{t \geq 0}|u(t)|$. Concerning these spaces, we have

Lemma 2.1 ([4]). On $H_{0, p}^{1}$, the quantity $\|u\|=\sqrt{\int_{0}^{+\infty} p(t) u^{\prime}(t)^{2} d t}$ defines a norm which is equivalent to the $H_{0, p}^{1}$-norm.

LEMMA $2.2([4])$.

(a) $H_{0, p}^{1}$ is continuously embedded in $C_{0}$, more precisely for every $u \in H_{0, p}^{1}$, one has $\|u\|_{\infty} \leq d\|u\|$, where $d=\left(\int_{0}^{+\infty} 1 / p(s) d s\right)^{1 / 2}$.

(b) The embedding $H_{0, p}^{1} \hookrightarrow C_{0}$ is compact.

Consider the Hilbert space

$$
L_{q}^{2}=\left\{u:(0,+\infty) \rightarrow \mathbb{R} \text { measurable such that } \sqrt{q} u \in L^{2}(0,+\infty)\right\}
$$

equipped with the norm

$$
\|u\|_{L_{q}^{2}}=\sqrt{\int_{0}^{+\infty} q(t) u^{2}(t) d t} .
$$

Since $\|u\|_{L_{q}^{2}}^{2} \leq\|u\|_{\infty}^{2}\|q\|_{L^{1}}$, we have

Proposition 2.3. $C_{0}$ is continuously embedded in $L_{q}^{2}$.

Corollary 2.4. $H_{0, p}^{1}$ is compactly embedded in $L_{q}^{2}$.

We are now interested in the first eigenvalue $\lambda_{1}(q)$ of the linear problem:

$$
\left\{\begin{array}{l}
-\left(p(t) u^{\prime}(t)\right)^{\prime}=\lambda q(t) u(t), \quad t>0 \\
u(0)=u(+\infty)=0
\end{array}\right.
$$

namely

$$
\lambda_{1}(q)=\inf _{u \in H_{0, p}^{1} \backslash\{0\}} \frac{\|u\|^{2}}{\|u\|_{L_{q}^{2}}^{2}} .
$$

REMARK 2.5. Notice that no impulse functions are involved in the linear problem (2.1). The reason is that only the characterization and the positivity of $\lambda_{1}(q)$ are needed (see the proof of Theorem 2.9, Step 1). Likewise the characterization of the associated eigenfunction $\varphi_{1}$ will be used in the proof of Theorem 2.9, Step 3. 
We have

Lemma 2.6. $\lambda_{1}(q)$ is positive and is achieved for some positive function $\varphi_{1}$ in $H_{0, p}^{1} \backslash\{0\}$.

Proof. For $u \in H_{0, p}^{1}$, let $I_{1}(u)=\|u\|^{2}, I_{2}(u)=\|u\|_{L_{q}^{2}}^{2}$, and define the quotient functional $Q: H_{0, p}^{1} \backslash\{0\} \rightarrow \mathbb{R}$ by

$$
Q(u)=\frac{I_{1}(u)}{I_{2}(u)} .
$$

Then $\lambda_{1}(q)=\inf _{u \in H_{0, p}^{1} \backslash\{0\}} Q(u)$.

Step 1. Using the Poincaré inequality, we have that $\lambda_{1}(q) \geq 1 / M_{2}>0$. Indeed

$$
\begin{aligned}
|u(t)|^{2} & =\left|\int_{t}^{+\infty} u^{\prime}(s) d s\right|^{2}=\left|\int_{t}^{+\infty} \sqrt{p(s)} u^{\prime}(s) \frac{1}{\sqrt{p(s)}} d s\right|^{2} \\
& \leq\left(\int_{t}^{+\infty} p(s) u^{\prime 2}(s) d s\right)\left(\int_{t}^{+\infty} \frac{d s}{p(s)}\right) \\
& \leq\left(\int_{0}^{+\infty} p(s) u^{\prime 2}(s) d s\right)\left(\int_{t}^{+\infty} \frac{d s}{p(s)}\right) .
\end{aligned}
$$

Hence

$$
q(t) u(t)^{2} \leq\left(\int_{0}^{+\infty} p(s) u^{\prime 2}(s) d s\right)\left(q(t) \int_{t}^{+\infty} \frac{d s}{p(s)}\right),
$$

i.e. $\|u\|_{L_{q}^{2}}^{2} \leq M_{2}\|u\|^{2}$, which implies $\|u\|^{2} /\|u\|_{L_{q}^{2}}^{2} \geq 1 / M_{2}>0$. Passing to the infimum yields

$$
\lambda_{1}(q)=\inf _{u \in H_{0, p}^{1} \backslash\{0\}} \frac{\|u\|^{2}}{\|u\|_{L_{q}^{2}}^{2}} \geq \frac{1}{M_{2}}>0 .
$$

Step 2. Let $\left(u_{n}\right)$ be a minimizing sequence. Since $\left(\left|u_{n}\right|\right)$ is a minimizing sequence for $Q$, we may suppose that $u_{n}(t) \geq 0$, for $t \in[0,+\infty)$. Moreover, the functional $Q$ satisfies $Q(\alpha u)=Q(u)$, for every $\alpha \in \mathbb{R}$; by setting $\widetilde{u_{n}}=u_{n} /\|u\|_{L_{q}^{2}}$, for every $n$, we can assume that $\left\|u_{n}\right\|_{L_{q}^{2}}=1$. Then $\left(I_{1}\left(u_{n}\right)\right)$ must be bounded independently of $n$. In fact,

$$
\lim _{n \rightarrow+\infty} Q\left(u_{n}\right)=\inf _{u \in H_{0, p}^{1} \backslash\{0\}} Q(u)=\lambda_{1}(q) .
$$

So the sequence $\left(Q\left(u_{n}\right)\right)$ is bounded. From this and since $Q\left(u_{n}\right)=\left\|u_{n}\right\|^{2}$, we deduce that $\left(u_{n}\right)$ is bounded in $H_{0, p}^{1}$. By Lemma 2.2(b) and the reflexivity and separability of $H_{0, p}^{1}$, there exists a subsequence $\left(u_{n_{k}}\right)$ of $\left(u_{n}\right)$ such that, as $k \rightarrow+\infty$,

$$
u_{n_{k}} \rightarrow \bar{u} \quad \text { in }, H_{0, p}^{1}, \quad u_{n_{k}} \rightarrow \bar{u} \quad \text { in } C_{0},
$$

so $u_{n_{k}}(t) \rightarrow \bar{u}(t)$, for all $t \in[0,+\infty)$. By Corollary $2.4,\left(u_{n_{k}}\right)$ converges in norm to $\bar{u}$ in $L_{q}^{2}$; thus $\|\left.\bar{u}\right|_{L_{q}^{2}}=1$ and $\bar{u}(t) \geq 0$, for $t \in[0,+\infty)$. Finally, the weak 
lower semi-continuity of the norm guarantees that

$$
Q(\bar{u})=I_{1}(\bar{u}) \leq \liminf _{k} I_{1}\left(u_{n_{k}}\right)=\liminf _{k} Q\left(u_{n_{k}}\right)=\lambda_{1}(q),
$$

so $\bar{u} \in H_{0, p}^{1} \backslash\{0\}$ and $Q(\bar{u})=\lambda_{1}(q)$.

Now, we define what we mean by a solution of problem (1.1).

Definition 2.7. We say that $u$ is a weak solution of problem (1.1) if

$$
\int_{0}^{+\infty} p(t) u^{\prime}(t) v^{\prime}(t) d t+\sum_{j=1}^{\infty} h\left(t_{j}\right) I_{j}\left(u\left(t_{j}\right)\right) v\left(t_{j}\right)=\int_{0}^{+\infty} q(t) f(t, u(t)) v(t) d t,
$$

for all $v \in H_{0, p}^{1}$, the limits $p\left(t_{j}^{+}\right) u^{\prime}\left(t_{j}^{+}\right)$and $p\left(t_{j}^{-}\right) u^{\prime}\left(t_{j}^{-}\right), j=1,2, \ldots$ exist and the impulsive conditions in problem (1.1) hold.

REMARK 2.8. If $u$ were in $H_{0, p}^{1}$ with $u^{\prime \prime} \in L^{2}$, then $u$ would be of $C^{1}$-class and so no impulsive conditions exist for $u^{\prime}$. If $u \in H_{0, p}^{1}$, then $u$ is absolutely continuous and $\sqrt{p} u^{\prime} \in L^{2}$. In this case $\triangle\left(p\left(t_{j}\right) u^{\prime}\left(t_{j}\right)\right)=p\left(t_{j}^{+}\right) u^{\prime}\left(t_{j}^{+}\right)-p\left(t_{j}^{-}\right) u^{\prime}\left(t_{j}^{-}\right)=0$ does not necessarily hold and the derivative $\sqrt{p} u^{\prime}$ may present some discontinuities, leading to the impulsive effects.

In [16] (see also [8], [20] and references therein), the definition of a classical solution is also introduced with $u \in H^{2}\left(t_{j}, t_{j+1}\right)$, which is natural, and $u$ satisfies the first equation of the considered impulsive boundary value problem, namely $-u^{\prime \prime}(t)+\lambda u(t)=\sigma(t)$, for almost every $t \in[0, T]$. Unfortunately this cannot hold almost everywhere on $[0, T]$ for otherwise $u \in H^{1}$ and $\sigma \in L^{2}(0, T)$ imply $u \in H^{2}(0, T)$ and as a consequence $u^{\prime}$ has no discontinuity at the impulsive point $t_{j}$, as the authors of [16] have previously noticed. In fact, the equation should be understood only in the distributional sense, i.e.

$$
-u^{\prime \prime}(t)+\lambda u(t)=\sigma(t)+\sum_{j=1}^{n} \Delta u^{\prime}\left(t_{j}\right) \delta_{j}, \quad t \in[0, T],
$$

where $\delta_{j}$ is the Dirac mass distribution defined by

$$
\left\langle\sum_{j=1}^{n} \Delta u^{\prime}\left(t_{j}\right) \delta_{j}, \varphi\right\rangle=\sum_{j=1}^{n} \Delta u^{\prime}\left(t_{j}\right) \varphi\left(t_{j}\right), \quad \text { for all } \varphi \in \mathcal{D}(0, T) ;
$$

here $\langle\cdot, \cdot\rangle=\langle\cdot, \cdot\rangle_{\mathcal{D}, \mathcal{D}^{\prime}}$ stands for the distribution pairing. Of course, we have that $-u^{\prime \prime}(t)+\lambda u(t)=\sigma(t)$, for all $t \in\left(t_{j}, t_{j+1}\right)$ and, for $j \in\{1, \ldots, n\}, t \neq t_{j}$ merely means $t \in\left(t_{j}, t_{j+1}\right), j \in\{1, \ldots, n\}$. This justifies the above definition of weak solution.

We are now ready to state our first existence result.

Theorem 2.9. Assume that the following conditions hold:

$\left(\mathrm{H}_{1}\right) f(t, 0)=0$, for $t \in[0,+\infty)$, 
$\left(\mathrm{H}_{2}\right)$ there exist $\alpha, \beta \in \mathbb{R}^{+}$with $\alpha<\lambda_{1}(q)$ such that

$$
|f(t, u)| \leq \alpha|u|+\beta, \quad \text { for all }(t, u) \in[0,+\infty) \times \mathbb{R},
$$

$\left(\mathrm{H}_{3}\right)$ there exists $\varepsilon_{0}>0$ such that $\left|f_{u}^{\prime}(t, 0)\right| \leq \lambda_{1}(q)-\varepsilon_{0}$, for all positive $t$, where $f_{u}^{\prime}(t, u)$ denotes the first-order derivative of $f$ in the second argument $u$,

$\left(\mathrm{H}_{4}\right)$ there exist $\delta>0, C_{1} \in \mathbb{R}$, and $\eta \in[0,1)$ such that

$$
f(t, u) \geq C_{1} u^{\eta}, \quad \text { for all } t \geq 0, u \in[0, \delta],
$$

$\left(\mathrm{H}_{5}\right) I_{j}^{\prime}(0)=0, j \in\{1,2, \ldots\}$,

$\left(\mathrm{H}_{6}\right)$ there exist $k>0$ and $\sigma \in(\eta, 1)$ such that $\left|I_{j}(s)\right| \leq k|s|^{\sigma}$, for all $s \in \mathbb{R}$, $j \in\{1,2, \ldots\}$.

Then problem (1.1) has at least three distinct weak solutions in $H_{0, p}^{1}$, one of them is the trivial solution.

The functional $J: H_{0, p}^{1} \rightarrow \mathbb{R}$ associated with problem (1.1) is defined by

$$
J(u)=\frac{1}{2}\|u\|^{2}+\sum_{j=1}^{\infty} h\left(t_{j}\right) \int_{0}^{u\left(t_{j}\right)} I_{j}(s) d s-\int_{0}^{+\infty} q(t) F(t, u(t)) d t,
$$

where $F(t, u)=\int_{0}^{u} f(t, v) d v$. Let the operator $A$ be defined by

$$
A u(t)=\int_{0}^{+\infty} G(t, s) q(s) f(s, u(s)) d s-\sum_{j=1}^{+\infty} G\left(t, t_{j}\right) h\left(t_{j}\right) I_{j}\left(u\left(t_{j}\right)\right),
$$

where $G$ is the Green's function of the problem $-\left(p(t) u^{\prime}(t)\right)^{\prime}=u(0)=u(+\infty)=0$, namely

$$
G(t, s)=\frac{1}{\|1 / p\|_{L^{1}}} \begin{cases}\varphi_{1}(t) \varphi_{2}(s), & t \leq s \\ \varphi_{1}(s) \varphi_{2}(t), & s \leq t\end{cases}
$$

with fundamental system of solutions

$$
\varphi_{1}(t)=\int_{0}^{t} \frac{d s}{p(s)} \text { and } \varphi_{2}(t)=\int_{t}^{+\infty} \frac{d s}{p(s)} .
$$

It is easy to note that, by $\left(\mathrm{H}_{2}\right)$ and $\left(\mathrm{H}_{6}\right)$, the functional $J$ and the perator $A$ are well defined. Next, we study the compactness of $A$.

Lemma 2.10. Under assumptions $\left(\mathrm{H}_{2}\right)$ and $\left(\mathrm{H}_{6}\right)$, we have:

(a) A self-maps the Sobolev space $H_{0, p}^{1}$.

(b) $A$ is compact.

Proof. (a) Given $u \in H_{0, p}^{1}$, we show that $A u \in H_{0, p}^{1}$; the proof will be performed in three steps:

Step 1. $A u \in A C([0,+\infty))$.

(i) The continuity of $A u$ follows from that of the Green's function, assumptions $\left(\mathrm{H}_{2}\right),\left(\mathrm{H}_{6}\right)$ and the Lebesgue dominated convergence theorem. 
(ii) $(A u)^{\prime} \in L^{1}(0,+\infty)$. We have

$$
\begin{aligned}
\left|(A u)^{\prime}(t)\right|= & \left|\int_{0}^{+\infty} G_{t}^{\prime}(t, s) q(s) f(s, u(s)) d s-\sum_{j=1}^{+\infty} G_{t}^{\prime}\left(t, t_{j}\right) h\left(t_{j}\right) I_{j}\left(u\left(t_{j}\right)\right)\right| \\
\leq & \int_{0}^{+\infty}\left|G_{t}^{\prime}(t, s)\right| q(s)|f(s, u(s))| d s \\
& +\sum_{j=1}^{+\infty}\left|G_{t}^{\prime}\left(t, t_{j}\right)\right|\left|h\left(t_{j}\right)\right||| I_{j}\left(u\left(t_{j}\right)\right) \mid \\
\leq & \frac{1}{p(t)} \int_{0}^{+\infty} q(s)|f(s, u(s))| d s+\frac{1}{p(t)} \sum_{j=1}^{+\infty}\left|h\left(t_{j}\right)\right|\left|I_{j}\left(u\left(t_{j}\right)\right)\right| .
\end{aligned}
$$

This together with $\left(\mathrm{H}_{2}\right)$ and $\left(\mathrm{H}_{6}\right)$ guarantee that $\int_{0}^{+\infty}\left|(A u)^{\prime}(t)\right| d t<\infty$.

Step 2. $G(0, s)=0$, for all $s \geq 0$ and $\lim _{t \rightarrow+\infty} G(t, s)=0$, for all $s \geq 0$; hence $A u(0)=A u(+\infty)=0$.

Step 3. $\sqrt{p}(A u)^{\prime} \in L^{2}(0,+\infty)$. From the inequality (2.4), we obtain that

$$
\begin{aligned}
p(t)\left|(A u)^{\prime}(t)\right|^{2} \leq & \frac{1}{p(t)}\left(\int_{0}^{+\infty} q(s)|f(s, u(s))| d s\right)^{2}+\frac{1}{p(t)}\left(\sum_{j=1}^{+\infty}\left|h\left(t_{j}\right)\right||| I_{j} u\left(t_{j}\right) \mid\right)^{2} \\
& +\frac{2}{p(t)}\left(\int_{0}^{+\infty} q(s)|f(s, u(s))| d s\right)\left(\sum_{j=1}^{\infty}\left|h\left(t_{j}\right)\right| \mid I_{j}\left(u\left(t_{j}\right) \mid\right),\right.
\end{aligned}
$$

and then $\left(H_{2}\right)$ and $\left(H_{6}\right)$ imply that $\int_{0}^{+\infty} p(t)\left|(A u)^{\prime}(t)\right|^{2} d t<+\infty$.

(b) Let $\left(u_{n}\right)$ be a bounded sequence in the reflexive separable space $H_{0, p}^{1}$. Then there exists a subsequence $\left(u_{n_{k}}\right)$ such that $u_{n_{k}} \rightarrow u$ in $H_{0, p}^{1}$, as $k \rightarrow+\infty$. We will prove that the sequence $\left(A u_{n_{k}}\right)$ is convergent. We have the estimates:

$$
\begin{aligned}
\left\|A u_{n_{k}}-A u\right\|= & \sup _{\|v\| \leq 1}\left|\left(A u_{n_{k}}-A u, v\right)\right| \\
= & \sup _{\|v\| \leq 1}\left|\int_{0}^{\infty} p(t)\left(A u_{n_{k}}-A u\right)^{\prime}(t) v^{\prime}(t) d t\right| \\
= & \sup _{\|v\| \leq 1} \mid \int_{0}^{+\infty}-\left(p(t)\left(A u_{n_{k}}-A u\right)^{\prime}(t)\right)^{\prime} v(t) d t \\
& +\sum_{j=1}^{+\infty} h\left(t_{j}\right)\left[I_{j}\left(u_{n_{k}}\left(t_{j}\right)\right)-I_{j}\left(u\left(t_{j}\right)\right)\right] v\left(t_{j}\right) \mid \\
= & \sup _{\|v\| \leq 1} \mid \int_{0}^{+\infty}\left[-\left(p(t)\left(A u_{n_{k}}\right)^{\prime}(t)\right)^{\prime}-\left(-p(t)(A u)^{\prime}(t)\right)^{\prime}\right] v(t) d t \\
& +\sum_{j=1}^{+\infty} h\left(t_{j}\right)\left[I_{j}\left(u_{n_{k}}\left(t_{j}\right)\right)-I_{j}\left(u\left(t_{j}\right)\right)\right] v\left(t_{j}\right) \mid
\end{aligned}
$$




$$
\begin{aligned}
= & \sup _{\|v\| \leq 1} \mid \int_{0}^{+\infty} q(t)\left[f\left(t, u_{n_{k}}(t)\right)-f(t, u(t))\right] v(t) d t \\
& +\sum_{j=1}^{+\infty} h\left(t_{j}\right)\left[I_{j}\left(u_{n_{k}}\left(t_{j}\right)\right)-I_{j}\left(u\left(t_{j}\right)\right)\right] v\left(t_{j}\right) \mid \\
\leq & \sup _{\|v\| \leq 1}\left[\int_{0}^{+\infty}\|v\|_{\infty} q(t)\left|f\left(t, u_{n_{k}}(t)\right)-f(t, u(t))\right| d t\right. \\
& \left.+\sum_{j=1}^{+\infty}\|v\|_{\infty}\left|h\left(t_{j}\right) \| I_{j}\left(u_{n_{k}}\left(t_{j}\right)\right)-I_{j}\left(u\left(t_{j}\right)\right)\right|\right] \\
\leq & d \sup _{\|v\| \leq 1}\left[\int_{0}^{+\infty}\|v\| q(t)\left|f\left(t, u_{n_{k}}(t)\right)-f(t, u(t))\right| d t\right. \\
& \left.+\sum_{j=1}^{+\infty}\|v\|\left\|h\left(t_{j}\right)\right\| I_{j}\left(u_{n_{k}}\left(t_{j}\right)\right)-I_{j}\left(u\left(t_{j}\right)\right) \mid\right] \\
\leq & d \int_{0}^{\infty} q(t)\left|f\left(t, u_{n_{k}}(t)\right)-f(t, u(t))\right| d t \\
& +d \sum_{j=1}^{+\infty}\left|h\left(t_{j}\right) \| I_{j}\left(u_{n_{k}}\left(t_{j}\right)\right)-I_{j}\left(u\left(t_{j}\right)\right)\right| .
\end{aligned}
$$

Using Lemma 2.2(b), $\left(\mathrm{H}_{2}\right),\left(\mathrm{H}_{6}\right)$, and the Lebesgue dominated convergence theorem, we obtain that $\left\|A u_{n_{k}}-A u\right\| \rightarrow 0$, as $k \rightarrow+\infty$. The same estimates show that $\left\|A u_{n}-A u\right\| \rightarrow 0$ whenever $\left\|u_{n}-u\right\| \rightarrow 0$, as $n \rightarrow+\infty$. The compactness of $A$ is then proved. In the same way, one can show that $A$ is continuous.

The properties of the first and second derivatives of $J$ are now studied.

Lemma 2.11. We have:

(a) Under assumptions $\left(\mathrm{H}_{2}\right)$ and $\left(\mathrm{H}_{6}\right), J$ is continuously differentiable and satisfies

$$
\begin{aligned}
\left(J^{\prime}(u), v\right)=\int_{0}^{+\infty} p(t) & u^{\prime}(t) v^{\prime}(t) d t \\
& +\sum_{j=1}^{\infty} h\left(t_{j}\right) I_{j}\left(u\left(t_{j}\right)\right) v\left(t_{j}\right)-\int_{0}^{+\infty} q(t) f(t, u(t)) v(t) d t
\end{aligned}
$$

for all $u, v \in H_{0, p}^{1}$ and $J^{\prime}=I-A$.

(b) Under assumptions $\left(\mathrm{H}_{3}\right)$ and $\left(\mathrm{H}_{5}\right), J^{\prime \prime}(\theta)$ exists, is continuous, and, for all $v, w \in H_{0, p}^{1}$, satisfies

$$
\left(J^{\prime \prime}(\theta) v, w\right)=\int_{0}^{+\infty} p(t) v^{\prime}(t) w^{\prime}(t) d t
$$




$$
+\sum_{j=1}^{\infty} h\left(t_{j}\right) I_{j}^{\prime}(0) v\left(t_{j}\right) w\left(t_{j}\right)-\int_{0}^{+\infty} q(t) f_{u}^{\prime}(t, 0) v(t) w(t) d t .
$$

Proof. (a) We only check that $J^{\prime}$ is well defined and $J^{\prime}=I-A$. From the Cauchy-Schwarz inequality, $\left(\mathrm{H}_{2}\right)$, and $\left(\mathrm{H}_{6}\right)$, we obtain for all $u, v \in H_{0, p}^{1}$ that:

$$
\left|\left(J^{\prime}(u), v\right)\right| \leq\left(1+k d^{\sigma+1} \sum_{j=1}^{+\infty}\left|h\left(t_{j}\right)\right|+\left(d^{2} \alpha+\beta\right)\|q\|_{L^{1}}\right)\|u\|\|v\|<\infty .
$$

Moreover, it can be easily checked that (see Remark 2.8)

$$
-\left(p(t)(A u)^{\prime}(t)\right)^{\prime}=q(t) f(t, u(t))+\sum_{j=1}^{\infty} \delta_{t=t_{j}} h\left(t_{j}\right) I_{j}\left(u\left(t_{j}\right)\right), \quad t \geq 0 .
$$

Hence $-\left(p(t)(A u)^{\prime}(t)\right)^{\prime}=q(t) f(t, u(t)), t \neq t_{j}, j \in\{1,2, \ldots\}$ and as a consequence

$$
\begin{aligned}
\left(J^{\prime}(u), v\right)= & (u, v)_{H_{0, p}^{1}}+\sum_{j=1}^{\infty} h\left(t_{j}\right) I_{j}\left(u\left(t_{j}\right)\right) v\left(t_{j}\right)-\int_{0}^{+\infty}-\left(p(t)(A u)^{\prime}(t)\right)^{\prime} v(t) d t \\
= & (u, v)_{H_{0, p}^{1}}+\sum_{j=1}^{\infty} h\left(t_{j}\right) I_{j}\left(u\left(t_{j}\right)\right) v\left(t_{j}\right) \\
& -\int_{0}^{+\infty} p(t)(A u)^{\prime}(t) v^{\prime}(t) d t-\sum_{j=1}^{\infty} h\left(t_{j}\right) I_{j}\left(u\left(t_{j}\right)\right) v\left(t_{j}\right) \\
= & (u, v)_{H_{0, p}^{1}}-(A u, v)_{H_{0, p}^{1}}=(u-A u, v)_{H_{0, p}^{1}},
\end{aligned}
$$

as claimed.

(b) Under assumptions $\left(\mathrm{H}_{3}\right)$ and $\left(\mathrm{H}_{5}\right),\left(J^{\prime \prime}(\theta) v, w\right)$ is well defined for all $v, w \in H_{0, p}^{1}(0,+\infty)$. Indeed, using $\left(\mathrm{H}_{3}\right),\left(\mathrm{H}_{5}\right)$, and again the Cauchy-Schwarz inequality, we obtain for all $v, w \in H_{0, p}^{1}$ that

$$
\begin{aligned}
\left|\left(J^{\prime \prime}(\theta) v, w\right)\right|= & \mid \int_{0}^{+\infty} p(t) v^{\prime}(t) w^{\prime}(t) d t+\sum_{j=1}^{\infty} h\left(t_{j}\right) I_{j}^{\prime}(0) v\left(t_{j}\right) w\left(t_{j}\right) \\
& -\int_{0}^{+\infty} q(t) f_{u}^{\prime}(t, 0) v(t) w(t) d t \mid \\
\leq & |(v, w)|+\int_{0}^{+\infty} q(t)\left|f_{u}^{\prime}(t, 0) \| v(t)\right||w(t)| d t \\
\leq & \left(1+d^{2}\|q\|_{L^{1}}\left(\lambda_{1}(q)-\varepsilon_{0}\right)\right)\|v\|\|w\|<+\infty .
\end{aligned}
$$

Finally, the continuity of $J^{\prime \prime}(\theta)$ is easily proved using the Lebesgue dominated convergence theorem.

Lemma 2.11 tells us that critical points of $J$, i.e. weak solutions of problem (1.1), are precisely fixed points of $A$.

We are now in position to prove Theorem 2.9. 
Proof of TheOREM 2.9. We have to prove that $J$ has at least three distinct critical points in $H_{0, p}^{1}$. To this end, it is sufficient to show that $J$ satisfies the hypotheses of Lemma 1.3 (see also Remark 1.6). The proof is split into five steps.

Step 1. There exists a constant $C>0$ such that

$$
\left\|J^{\prime \prime}(\theta) v\right\| \geq C\|v\|^{2}, \quad \text { for all } v \in H_{0, p}^{1} .
$$

We proceed as in [11, Lemma 3.2]). From the Cauchy-Schwarz inequality, we have

$$
\left\|J^{\prime \prime}(\theta) v\right\|\|v\| \geq\left(J^{\prime \prime}(\theta) v, v\right), \quad \text { for all } v \in H_{0, p}^{1} .
$$

Using $\left(\mathrm{H}_{3}\right)$ and $\left(\mathrm{H}_{5}\right)$, we get

$$
\begin{aligned}
\left(J^{\prime \prime}(\theta) v, v\right) & =\|v\|^{2}-\int_{0}^{+\infty} q(t) f_{u}^{\prime}(t, 0)(v(t))^{2} d t \\
& \geq\|v\|^{2}-\int_{0}^{+\infty}\left(\lambda_{1}(q)-\varepsilon_{0}\right) q(t)(v(t))^{2} d t \\
& \geq\|v\|^{2}-\left(\lambda_{1}(q)-\varepsilon_{0}\right) \int_{0}^{+\infty} q(t)(v(t))^{2} d t \\
& =\|v\|^{2}-\frac{\lambda_{1}(q)-\varepsilon_{0}}{\lambda_{1}(q)} \lambda_{1}(q)\|v\|_{L_{q}^{2}}^{2} \\
& \geq\left(1-\frac{\lambda_{1}(q)-\varepsilon_{0}}{\lambda_{1}(q)}\right)\|v\|^{2}=\frac{\varepsilon_{0}}{\lambda_{1}(q)}\|v\|^{2}
\end{aligned}
$$

for all $v \in H_{0, p}^{1}$, proving our claim.

Step 2. $J$ is bounded from below on $H_{0, p}^{1}$. Indeed, $\left(\mathrm{H}_{2}\right)$ implies that

$$
F(t, u) \leq \frac{\alpha}{2} u^{2}+\beta|u|, \quad \text { for all }(t, u) \in[0,+\infty) \times \mathbb{R},
$$

where $F(t, u)=\int_{0}^{u} f(t, v) d v$. Then from (2.6), $\left(\mathrm{H}_{6}\right)$, and Lemmas 2.2, 2.4, we have the estimates, for all $u \in H_{0, p}^{1}$,

$$
\begin{aligned}
J(u)= & \frac{1}{2}\|u\|^{2}+\sum_{j=1}^{\infty} h\left(t_{j}\right) \int_{0}^{u\left(t_{j}\right)} I_{j}(s) d s-\int_{0}^{+\infty} q(t) F(t, u(t)) d t \\
\geq & \frac{1}{2}\|u\|^{2}-\frac{k \sum_{j=1}^{\infty}\left|h\left(t_{j}\right)\right|}{\sigma+1}\left|u\left(t_{j}\right)\right|^{\sigma+1} \\
& -\frac{\alpha}{2} \int_{0}^{+\infty} q(t)|u(t)|^{2} d t-\beta \int_{0}^{+\infty} q(t)|u(t)| d t \\
\geq & \frac{1}{2}\|u\|^{2}-\frac{k \sum_{j=1}^{\infty}\left|h\left(t_{j}\right)\right|}{\sigma+1}\|u\|_{\infty}^{\sigma+1} \\
& -\frac{\alpha}{2 \lambda_{1}(q)} \lambda_{1}(q)\|u\|_{L_{q}^{2}}^{2}-\beta\left\|_{q}\right\|_{L^{1}}\|u\|_{\infty}
\end{aligned}
$$




$$
\geq\left(\frac{1}{2}-\frac{\alpha}{2 \lambda_{1}(q)}\right)\|u\|^{2}-d \beta\|q\|_{L^{1}}\|u\|-\frac{k d^{\sigma+1} \sum_{j=1}^{\infty}\left|h\left(t_{j}\right)\right|}{\sigma+1}\|u\|^{\sigma+1},
$$

and our claim follows.

Step 3. $\theta$ is not a global minimum. Let $\varphi_{1}$ the eigenfunction associated with the eigenvalue $\lambda_{1}(q)$ and let $\xi$ be such that $0<\xi \leq \delta /\left\|\varphi_{1}\right\|_{\infty}$. From $\left(\mathrm{H}_{4}\right)$ and $\left(\mathrm{H}_{6}\right)$, we derive the estimates:

$$
\begin{aligned}
& J\left(\xi \varphi_{1}\right)=\frac{1}{2} \xi^{2}\left\|\varphi_{1}\right\|^{2}+\sum_{j=1}^{+\infty} h\left(t_{j}\right) \int_{0}^{\xi \varphi_{1}\left(t_{j}\right)} I_{j}(s) d s-\int_{0}^{+\infty} q(t) F\left(t, \xi \varphi_{1}(t)\right) d t \\
& \leq \frac{1}{2} \xi^{2}\left\|\varphi_{1}\right\|^{2}+\xi^{\sigma+1} \frac{k \sum_{j=1}^{+\infty}\left|h\left(t_{j}\right)\right|}{\sigma+1}\left(\varphi_{1}\left(t_{j}\right)\right)^{\sigma+1}-\frac{1}{\eta+1} \int_{0}^{+\infty} C_{1} q(t)\left(\xi \varphi_{1}(t)\right)^{\eta+1} d t \\
& \leq \frac{1}{2} \xi^{2}\left\|\varphi_{1}\right\|^{2}+\xi^{\sigma+1} \frac{k \sum_{j=1}^{+\infty}\left|h\left(t_{j}\right)\right|}{\sigma+1}\left\|\varphi_{1}\right\|_{\infty}^{\sigma+1}-\frac{\xi^{\eta+1} C_{1}}{\eta+1} \int_{0}^{+\infty} q(t)\left(\varphi_{1}(t)\right)^{\eta+1} d t \\
& \leq \frac{1}{2}\left\|\varphi_{1}\right\|^{2} \xi^{2}+\frac{k d^{\sigma+1} \sum_{j=1}^{+\infty}\left|h\left(t_{j}\right)\right|}{\sigma+1}\left\|\varphi_{1}\right\|^{\sigma+1} \xi^{\sigma+1}-\frac{C_{1}}{\eta+1}\left\|\varphi_{1}\right\|_{L_{q}^{\eta+1}}^{\eta+1} \xi^{\eta+1},
\end{aligned}
$$

where

$$
\left\|\varphi_{1}\right\|_{L_{q}^{\eta+1}}=\left(\int_{0}^{\infty} q(t)\left|\varphi_{1}(t)\right|^{\eta+1} d t\right)^{1 /(\eta+1)} \leq \widetilde{k}\left\|\varphi_{1}\right\|_{L_{q}^{2}}<+\infty
$$

for some positive constant $\widetilde{k}$. Indeed, all norms are equivalent in the onedimensional space spanned by $\varphi_{1}$ (see $[12$, p. 86]). Now, since $0 \leq \eta<1$ and $\eta<\sigma$, then for sufficiently small $\xi$, the leading term of the right-hand polynomial is $\xi^{\eta+1}$. Hence there is some $\xi_{0}$ such that $J\left(\xi \varphi_{1}\right)<0=J(\theta)$, for $0<\xi \leq \xi_{0}$.

Step 4. $J$ satisfies the PS condition. Suppose that $\left(u_{n}\right) \subset H_{0, p}^{1}$ and there exists $M>0$ such that $\left|J\left(u_{n}\right)\right| \leq M$ and $J^{\prime}\left(u_{n}\right)=u_{n}-A u_{n} \rightarrow \theta$ in $H_{0, p}^{1}$, as $n \rightarrow$ $+\infty$. From $(2.7)$, we know that $\left(u_{n}\right)$ is bounded in $H_{0, p}^{1}$. By the compactness of $A: H_{0, p}^{1} \rightarrow H_{0, p}^{1}$ (Lemma 2.10), there exists a subsequence $\left(A u_{n_{k}}\right)$ such that $A\left(u_{n_{k}}\right) \rightarrow w$, as $k \rightarrow+\infty$. Then $\left\|u_{n_{k}}-w\right\| \leq\left\|u_{n_{k}}-A u_{n_{k}}\right\|+\left\|A u_{n_{k}}-w\right\|$ and since $u_{n_{k}}-A u_{n_{k}} \rightarrow \theta$ in $H_{0, p}^{1}$, as $k \rightarrow+\infty$, we obtain that $\left(u_{n}\right)$ has a convergent subsequence $\left(u_{n_{k}}\right)$ such that $u_{n_{k}} \rightarrow w$, as $k \rightarrow+\infty$. Therefore $J$ satisfies the PS condition on $H_{0, p}^{1}$.

Step 5. (a) $\theta$ is a critical point. From $\left(\mathrm{H}_{1}\right)$ and $\left(\mathrm{H}_{5}\right), \theta$ is a critical point of $J$ and $J(\theta)=0$.

(b) $\theta$ is nondegenerate. From Step 1 and Lemma $1.8, J^{\prime \prime}(\theta)$ is invertible, so $\theta$ is nondegenerate. 
(c) The Morse index is finite. From $(2.5), J^{\prime \prime}(\theta)$ is positive defined throughout the space $H_{0, p}^{1}$; then the Morse index of $J$ at $\theta$ is equal to 0 ; so it is finite and $j=0<+\infty$.

Conclusion. To sum up, we have proved that $\theta$ is a nondegenerate, non global minimum critical point and its Morse index is finite. By Lemma 1.3, we conclude that $J$ has at least three distinct critical points. Therefore problem (1.1) has at least three distinct weak solutions in $H_{0, p}^{1}$.

EXAMPLE 2.12. The following impulsive boundary value problem has at least three distinct weak solutions in $H_{0, p}^{1}$, including the trivial solution:

$$
\begin{cases}-\left(e^{t} u^{\prime}(t)\right)^{\prime}=\lambda_{1} e^{-t} \frac{u(t)+\sin u(t)}{4}, & t \neq t_{j}, j \in\{1,2, \ldots\}, t>0, \\ u(0)=u(+\infty)=0, & \\ \Delta\left(e^{t_{j}} u^{\prime}\left(t_{j}\right)\right)=\frac{1}{1+t_{j}^{2}} \frac{u\left(t_{j}\right)^{2}}{1+u\left(t_{j}\right)^{2}}, & j \in\{1,2, \ldots\},\end{cases}
$$

where $\lambda_{1}$ is the first eigenvalue of the linear problem:

$$
\left\{\begin{array}{l}
-\left(e^{t} u^{\prime}(t)\right)^{\prime}=\lambda e^{-t} u(t), \quad t>0, \\
u(0)=u(+\infty)=0 .
\end{array}\right.
$$

Indeed, we have:

$\left(\mathrm{H}_{1}\right) f(t, 0)=0$, for $t \in[0,+\infty)$,

$\left(\mathrm{H}_{2}\right)$ for $\alpha=\lambda_{1} / 2$ and $\beta=0$, we have $|f(t, u)| \leq \alpha|u|+\beta$,

$\left(\mathrm{H}_{3}\right)$ there exists $\varepsilon_{0} \in\left(0, \lambda_{1} / 2\right)$ such that $f_{u}^{\prime}(t, 0)=\lambda_{1} / 2 \leq \lambda_{1}-\varepsilon_{0}$,

$\left(\mathrm{H}_{4}\right)$ for $C_{1}=\lambda_{1} / 16, \eta=1 / 3$, we have $f(t, u) \geq C_{1} u^{\eta}$, whenever $u>0$ is small enough,

$\left(\mathrm{H}_{5}\right) I_{j}^{\prime}(u)=2 u /\left(1+u^{2}\right)^{2}$ and so $I_{j}^{\prime}(0)=0$,

$\left(\mathrm{H}_{6}\right)$ for $k=1, \sigma=1 / 2$, we have $\left|I_{j}(u)\right| \leq k|u|^{\sigma}$.

Regarding $\lambda_{1}$, the first eigenvalue of the linear problem (2.9), it has been computed for different values of a parameter $R$ for a problem posed on an interval $(0, R)$; it approaches 271.76159 for $R=60$ and then stabilized. The obtained values are depicted in the graph and table (see Figure 1).

Our second existence result of multiple solutions is now presented when $h$ is positive.

THEOREM 2.13. Assume that the following conditions hold:

$\left(\mathrm{L}_{1}\right)$ there exist $\nu>2$ and $C_{3}>0$ such that

$$
\nu F(t, u) \leq u f(t, u)+\nu C_{3}, \quad \text { for all } t \geq 0, u \in \mathbb{R},
$$

$\left(\mathrm{L}_{2}\right)$ there exist $C_{4}, C_{5} \in \mathbb{R}\left(C_{4}>0\right)$ such that

$$
F(t, u) \geq C_{4}|u|^{\nu}-C_{5}, \quad \text { for all } t \geq 0, u \in \mathbb{R},
$$




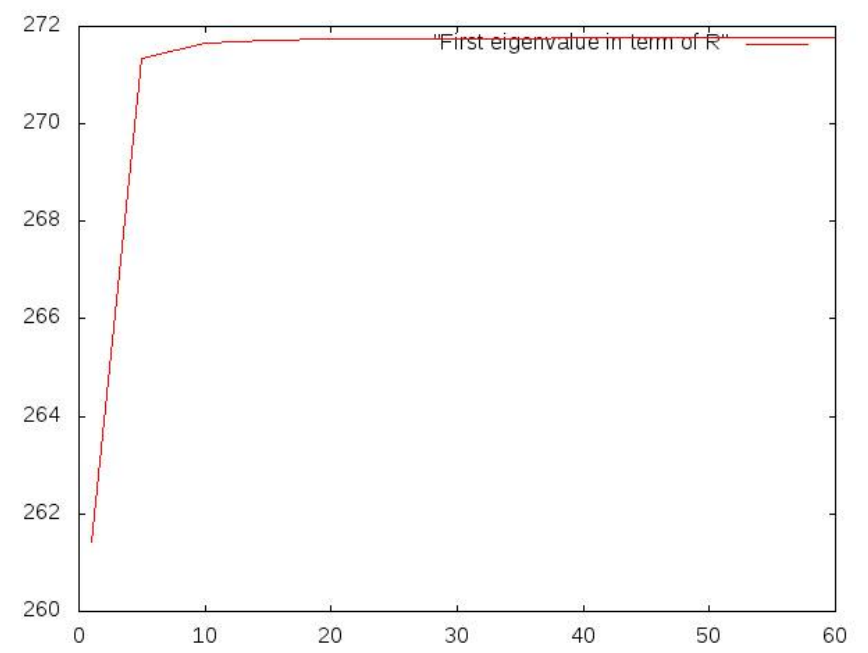

\begin{tabular}{|c|c||c|c|}
\hline $\mathrm{R}$ & $\lambda_{1}(R)$ & $\mathrm{R}$ & $\lambda_{1}(R)$ \\
\hline 1 & 261.43004 & 35 & 271.75596 \\
5 & 271.34599 & 40 & 271.75796 \\
10 & 271.65983 & 45 & 271.75933 \\
15 & 271.71798 & 50 & 271.76031 \\
20 & 271.73833 & 55 & 271.76104 \\
25 & 271.74775 & 60 & 271.76159 \\
30 & 271.75287 & & \\
\hline
\end{tabular}

Figure 1. Problem (2.9): $\lambda_{1}$ in terms of $R$.

( $\left.\mathrm{L}_{3}\right) f(t, u)$ is odd in $u$, i.e., $f(t,-u)=-f(t, u)$, for all $t \geq 0, u \in \mathbb{R}$,

$\left(\mathrm{L}_{4}\right)$ there exists a positive continuous function $g$ with

$$
|f(t, u)| \leq g(u), \quad \text { for all } t \geq 0, u \in \mathbb{R},
$$

( $\left.\mathrm{L}_{5}\right) I_{j}(\cdot)$ is odd $(j \in\{1,2, \ldots\})$,

$\left(\mathrm{L}_{6}\right)$ there exist $\mu<\nu$ such that

$$
\mu \int_{0}^{u} I_{j}(s) d s \geq u I_{j}(u)>0, \quad \text { for all } u \in \mathbb{R} \backslash\{0\}, j \in\{1,2, \ldots\} .
$$

Then problem (1.1) has infinitely many weak solutions in $H_{0, p}^{1}$.

Proof. We have to prove that $J$ has infinitely many critical points in $H_{0, p}^{1}$. The proof is split into two steps.

Step 1. $J$ satisfies the PS condition. Indeed, suppose that $\left(u_{n}\right) \subset H_{0, p}^{1}$ and there exists $M>0$ such that $\left|J\left(u_{n}\right)\right| \leq M$ and $J^{\prime}\left(u_{n}\right)=u_{n}-A u_{n} \rightarrow \theta$ in $H_{0, p}^{1}$, 
as $n \rightarrow+\infty$. Using $\left(\mathrm{L}_{1}\right)$ and $\left(\mathrm{L}_{6}\right)$, we get the estimates:

$$
\begin{aligned}
\nu J\left(u_{n}\right) & -\left(J^{\prime}\left(u_{n}\right), u_{n}\right) \\
= & \frac{\nu}{2}\left\|u_{n}\right\|^{2}+\nu \sum_{j=1}^{\infty} h\left(t_{j}\right) \int_{0}^{u_{n}\left(t_{j}\right)} I_{j}(s) d s-\int_{0}^{+\infty} \nu q(t) F(t, u(t)) d t \\
& -\left\|u_{n}\right\|^{2}-\sum_{j=1}^{\infty} h\left(t_{j}\right) I_{j}\left(u_{n}\left(t_{j}\right)\right) u_{n}\left(t_{j}\right)+\int_{0}^{+\infty} q(t) f\left(t, u_{n}(t)\right) u_{n}(t) d t \\
\geq & \left(\frac{\nu}{2}-1\right)\left\|u_{n}\right\|^{2}+\nu \sum_{j=1}^{+\infty} h\left(t_{j}\right) \int_{0}^{u_{n}\left(t_{j}\right)} I_{j}(s) d s \\
& -\int_{0}^{+\infty}\left[q(t) f\left(t, u_{n}(t)\right) u_{n}(t)+\nu C_{3} q(t)\right] d t \\
& -\sum_{j=1}^{\infty} h\left(t_{j}\right) I_{j}\left(u_{n}\left(t_{j}\right)\right) u_{n}\left(t_{j}\right)+\int_{0}^{+\infty} q(t) u_{n}(t) f\left(t, u_{n}(t)\right) d t \\
\geq & \left(\frac{\nu}{2}-1\right)\left\|u_{n}\right\|^{2}+\nu \sum_{j=1}^{\infty} h\left(t_{j}\right) \int_{0}^{u_{n}\left(t_{j}\right)} I_{j}(s) d s \\
& -\mu \sum_{j=1}^{\infty} h\left(t_{j}\right) \int_{0}^{u_{n}\left(t_{j}\right)} I_{j}(s) d s-\nu C_{3}\|q\|_{L^{1}} \\
\geq & \left(\frac{\nu}{2}-1\right)\left\|u_{n}\right\|^{2}+\nu \sum_{j=1}^{\infty} h\left(t_{j}\right) \int_{0}^{u_{n}\left(t_{j}\right)} I_{j}(s) d s \\
& -\nu \sum_{j=1}^{\infty} h\left(t_{j}\right) \int_{0}^{u_{n}\left(t_{j}\right)} I_{j}(s) d s-\nu C_{3}\|q\|_{L^{1}} \\
= & \left(\frac{\nu}{2}-1\right)\left\|u_{n}\right\|^{2}-\nu C_{3}\|q\|_{L^{1}} .
\end{aligned}
$$

Hence

$$
\begin{aligned}
J\left(u_{n}\right) & \geq\left(\frac{\nu}{2}-1\right)\left\|u_{n}\right\|^{2}+\frac{1}{\nu}\left(J^{\prime}\left(u_{n}\right), u_{n}\right)-C_{3}\|q\|_{L^{1}} \\
& \geq\left(\frac{\nu}{2}-1\right)\left\|u_{n}\right\|^{2}-\frac{1}{\nu}\left\|J^{\prime}\left(u_{n}\right)\right\|\left\|\mid u_{n}\right\|-C_{3}\|q\|_{L^{1}} .
\end{aligned}
$$

Since $J^{\prime}\left(u_{n}\right) \rightarrow 0$, as $n \rightarrow+\infty$, there exists $n_{0} \in \mathbb{N}$ such that

$$
M \geq J\left(u_{n}\right) \geq\left(\frac{\nu}{2}-1\right)\left\|u_{n}\right\|^{2}-\left\|u_{n}\right\|-C_{3}\|q\|_{L^{1}}, \quad \text { for } n>n_{0}
$$

which implies that $\left(u_{n}\right)$ is bounded. Since $A: H_{0, p}^{1} \rightarrow H_{0, p}^{1}$ is compact (see Lemma 2.10), $\left(u_{n}\right)$ has a convergent subsequence in $H_{0, p}^{1}$, and then $J$ satisfies the PS condition on $H_{0, p}^{1}$ (we proceed as in the proof of Theorem 2.9, Step 4).

From $\left(\mathrm{L}_{3}\right)$ and $\left(\mathrm{L}_{5}\right)$, we can see that $J$ is an even functional and $A$ is an odd operator. 
Step 2. We argue as in the proof of [11, Theorem 1.3]. By contradiction, assume that $J$ has at most a finite number of critical points $\left\{v_{1},-v_{1}, \ldots, v_{m},-v_{m}\right\}$. Let $a, b$ two real numbers such that $a<0$ and $b>0$ with

$$
\begin{aligned}
& a<\min \left\{J\left(v_{1}\right), \ldots, J\left(v_{m}\right),-C_{3}\|q\|_{L^{1}}\right\}, \\
& b>\max \left\{J\left(v_{1}\right), \ldots, J\left(v_{m}\right)\right\} .
\end{aligned}
$$

$\left(\mathrm{L}_{6}\right)$ implies that

$$
\int_{0}^{u} I_{j}(s) d s \leq|u|^{\mu}, \quad \text { for all } u \in \mathbb{R}
$$

Given $u \in H_{0, p}^{1}$, Assumption $\left(L_{2}\right)$ and (2.12) guarantee that

$$
\begin{aligned}
J(u) & =\frac{1}{2}\|u\|^{2}+\sum_{j=1}^{+\infty} h\left(t_{j}\right) \int_{0}^{u\left(t_{j}\right)} I_{j}(s) d s-\int_{0}^{+\infty} q(t) F(t, u(t)) d t \\
& \leq \frac{1}{2}\|u\|^{2}+\sum_{j=1}^{\infty} h\left(t_{j}\right) \int_{0}^{u\left(t_{j}\right)} I_{j}(s) d s-\int_{0}^{+\infty} q(t)\left(C_{4}|u(t)|^{\nu}-C_{5}\right) d t \\
& \leq \frac{1}{2}\|u\|^{2}+\sum_{j=1}^{\infty} h\left(t_{j}\right)\left|u\left(t_{j}\right)\right|^{\mu}-C_{4} \int_{0}^{+\infty} q(t)|u(t)|^{\nu} d t+\int_{0}^{\infty} C_{5} q(t) d t \\
& \leq \frac{1}{2}\|u\|^{2}+\sum_{j=1}^{\infty} h\left(t_{j}\right)\|u\|_{\infty}^{\mu}-C_{4} \int_{0}^{+\infty} q(t)|u(t)|^{\nu} d t+C_{5}\|q\|_{L^{1}} \\
& \leq \frac{1}{2}\|u\|^{2}+d^{\mu} \sum_{j=1}^{\infty} h\left(t_{j}\right)\|u\|^{\mu}-C_{4} \int_{0}^{+\infty} q(t)|u(t)|^{\nu} d t+C_{5}\|q\|_{L^{1}} .
\end{aligned}
$$

As a consequence

$$
J(u) \leq \frac{1}{2}\|u\|^{2}+d^{\mu} \sum_{j=1}^{\infty} h\left(t_{j}\right)\|u\|^{\mu}-C_{4} \int_{0}^{+\infty} q(t)|u(t)|^{\nu} d t+C_{5}\|q\|_{L^{1}} .
$$

Consider the unit sphere $S^{\infty}=\left\{u \in H_{0, p}^{1}:\|u\|=1\right\}$ in $H_{0, p}^{1}$. For $u \in S^{\infty}$ and $\tau>0$, we have

$$
J(\tau u) \leq \frac{1}{2} \tau^{2}+d^{\mu} \sum_{j=1}^{\infty} h\left(t_{j}\right) \tau^{\mu}-\tau^{\nu} C_{4} \int_{0}^{+\infty} q(t)|u(t)|^{\nu} d t+C_{5}\|q\|_{L^{1}} .
$$

In addition $\lim _{\tau \rightarrow+\infty} J(\tau u)=-\infty$. Since $a<0=J(\theta)$, then there exist $\tau=\gamma(u)$ and $\delta>0$ such that

$$
\gamma(u) \geq \delta \quad \text { and } \quad J(\gamma(u) u)=a
$$

Now, we show the uniqueness of the function $\gamma$ satisfying (2.13) (see [7, Lemma 5.1.38]). Indeed, for $u \in S^{\infty}$ and $\tau>0$, the assumptions $\left(\mathrm{L}_{1}\right),\left(\mathrm{L}_{6}\right)$ together 
with $\nu>2$ imply that

$$
\begin{aligned}
\frac{d}{d \tau}(J(\tau u))=\left(J^{\prime}(\tau u), u\right) \\
=(\tau u, u)+\sum_{j=1}^{+\infty} h\left(t_{j}\right) I_{j}\left(\tau u\left(t_{j}\right)\right) u\left(t_{j}\right)-\int_{0}^{+\infty} q(t) f(t, \tau u(t)) u(t) d t \\
\leq \tau+\frac{1}{\tau} \sum_{j=1}^{+\infty} h\left(t_{j}\right) I_{j}\left(\tau u\left(t_{j}\right)\right) \tau u\left(t_{j}\right)-\frac{\nu}{\tau} \int_{0}^{+\infty} q(t) F(t, \tau u(t)) d t \\
\quad+\frac{\nu C_{3}}{\tau} \int_{0}^{+\infty} q(t) d t \\
\leq \frac{\nu}{\tau}\left(\frac{1}{2} \tau^{2}+\frac{\mu}{\nu} \sum_{j=0}^{\infty} h\left(t_{j}\right) \int_{0}^{\tau u\left(t_{j}\right)} I_{j}(s) d s-\int_{0}^{+\infty} q(t) F(t, \tau u(t)) d t\right) \\
\quad+\frac{\nu C_{3}\|q\|_{L^{1}}}{\tau} \\
\leq \frac{\nu}{\tau}\left(\frac{1}{2} \tau^{2}+\sum_{j=1}^{\infty} h\left(t_{j}\right) \int_{0}^{\tau u\left(t_{j}\right)} I_{j}(s) d s-\int_{0}^{+\infty} q(t) F(t, \tau u(t)) d t\right) \\
\quad+\frac{\nu C_{3}\|q\|_{L^{1}}}{\tau} \\
=\frac{\nu}{\tau}(J(\tau u))+\frac{\nu C_{3}\|q\|_{L^{1}}}{\tau}=\frac{\nu}{\tau}\left(J(\tau u)+C_{3}\|q\|_{L^{1}}\right) .
\end{aligned}
$$

From (2.13) and (2.10) we obtain that

$$
\left.\frac{d}{d \tau} J(\tau u)\right|_{\tau=\gamma(u)} \leq \frac{\nu}{\tau}\left(J(\gamma(u) u)+C_{3}|| q \|_{L^{1}}\right)=\frac{\nu}{\tau}\left(a+C_{3}\|q\|_{L^{1}}\right)<0 .
$$

Thus, for $u \in H_{0, p}^{1}$, the continuous function $h(\tau)=J(\tau u)$ is strictly decreasing in the neighbourhood of $\tau=\gamma(u)$. From (2.13), we have that $\gamma(u)$ is unique.

Now we prove that $\gamma: S^{\infty} \rightarrow \mathbb{R}$ is continuous. Let $\left(u_{n}\right) \subset S^{\infty}, u_{0} \in S^{\infty}$, and $u_{n} \rightarrow u_{0}$ in $H_{0, p}^{1}$, as $n \rightarrow \infty$. From $\left(L_{2}\right)$ and (2.12), we have

$$
\begin{aligned}
a=J\left(\gamma\left(u_{n}\right) u_{n}\right)= & \frac{1}{2}\left\|\gamma\left(u_{n}\right) u_{n}\right\|^{2}+\sum_{j=1}^{\infty} h\left(t_{j}\right) \int_{0}^{\gamma\left(u_{n}\right) u_{n}} I_{j}(s) d s \\
& -\int_{0}^{+\infty} q(t) F\left(t, \gamma\left(u_{n}\right) u_{n}(t)\right) d t \\
\leq & \frac{1}{2}\left(\gamma\left(u_{n}\right)\right)^{2}+d^{\mu} \sum_{j=1}^{\infty} h\left(t_{j}\right)\left(\gamma\left(u_{n}\right)\right)^{\mu} \\
& -C_{4}\left(\gamma\left(u_{n}\right)\right)^{\nu} \int_{0}^{+\infty} q(t)\left|u_{n}(t)\right|^{\nu} d t+C_{5}\|q\|_{L^{1}} .
\end{aligned}
$$

Hence 


$$
\begin{aligned}
a \leq \frac{1}{2}\left(\gamma\left(u_{n}\right)\right)^{2}+d^{\mu} \sum_{j=1}^{\infty} & h\left(t_{j}\right)\left(\gamma\left(u_{n}\right)\right)^{\mu} \\
& \quad-C_{4}\left(\gamma\left(u_{n}\right)\right)^{\nu} \int_{0}^{+\infty} q(t)\left|u_{n}(t)\right|^{\nu} d t+C_{5}\|q\|_{L^{1}} .
\end{aligned}
$$

Moreover, $\left\|\sqrt[\nu]{q} u_{n}\right\|_{L^{\nu}}^{\nu} \rightarrow\left\|\sqrt[\nu]{q} u_{0}\right\|_{L^{\nu}}^{\nu}$, as $n \rightarrow+\infty$. As a consequence, there exist $C_{6}>0$ and $n_{0} \in \mathbb{N}$ such that $\int_{0}^{+\infty} q(t)\left|u_{n}(t)\right|^{\nu} d t \geq C_{6}$, for $n \geq n_{0}$. Therefore, from (2.14) we have

$a \leq \frac{1}{2}\left(\gamma\left(u_{n}\right)\right)^{2}+d^{\mu} \sum_{j=1}^{\infty} h\left(t_{j}\right)\left(\gamma\left(u_{n}\right)\right)^{\mu}-C_{4} C_{6}\left(\gamma\left(u_{n}\right)\right)^{\nu}+C_{5}\|q\|_{L^{1}}, \quad$ for $n \geq n_{0}$.

Then $\left(\gamma\left(u_{n}\right)\right)$ is bounded, hence it has a least one limiting point. Let $w$ be an arbitrary limiting point of $\left(\gamma\left(u_{n}\right)\right)$, i.e. there exists $\left(\gamma\left(u_{n_{k}}\right)\right)$ a subsequence of $\left(\gamma\left(u_{n}\right)\right)$ such that $\gamma\left(u_{n_{k}}\right) \rightarrow w$, as $k \rightarrow \infty$. Letting $k \rightarrow \infty$ in the equation $J\left(\gamma\left(u_{n_{k}}\right) u_{n_{k}}\right)=a$ yields $J\left(w u_{0}\right)=a$. From the uniqueness of $\gamma\left(u_{0}\right)$, we deduce that $w=\gamma\left(u_{0}\right)$; this implies that $\gamma\left(u_{n}\right) \rightarrow \gamma\left(u_{0}\right)$ as $n \rightarrow+\infty$, and then the map $\gamma: S^{\infty} \rightarrow \mathbb{R}$ is continuous.

Let $0<\varepsilon<\delta$ be such that $J^{a} \cap B_{\varepsilon}=\emptyset$, i.e. $J^{a} \subset H_{0, p}^{1} \backslash B_{\varepsilon}$, where $B_{\varepsilon}=\left\{u \in H_{0, p}^{1}:\|u\|<\varepsilon\right\}$. Define the mapping $\eta:[0,1] \times\left(H_{0, p}^{1} \backslash B_{\varepsilon}\right) \rightarrow H_{0, p}^{1} \backslash B_{\varepsilon}$ by

$$
\eta(s, u)= \begin{cases}(1-s) u+s \gamma\left(\frac{u}{\|u\|}\right)\left(\frac{u}{\|u\|}\right), & u \in\left(H_{0, p}^{1} \backslash B_{\varepsilon}\right) \backslash J^{a}, \\ u, & u \in J^{a} .\end{cases}
$$

(See also [7, p. 346], [11, p. 3654], and [21, p. 161]). From the continuity of $\gamma(\cdot), \eta$ is a continuous mapping which is a strong deformation retraction from $H_{0, p}^{1} \backslash B_{\varepsilon}$ to $J^{a}$. From (2.11), one can further construct a strong deformation retraction of $H_{0, p}^{1}$ in $J^{b}$. Then

$$
\beta_{k}=\beta_{k}(a, b)=\operatorname{dim} H_{k}\left(J^{b}, J^{a}\right)=\operatorname{dim} H_{k}\left(H_{0, p}^{1}, H_{0, p}^{1} \backslash B_{\varepsilon}\right) .
$$

Since $H_{0, p}^{1} \backslash B_{\varepsilon}$ is homotopically equivalent to $S^{\infty}$ and $S^{\infty}$ is contractible, we deduce that $H_{0, p}^{1} \backslash B_{\varepsilon}$ is contractible. Therefore

$$
H_{k}\left(H_{0, p}^{1}, H_{0, p}^{1} \backslash B_{\varepsilon}\right) \simeq 0 \quad \text { and } \quad \beta_{k}=0, \quad \text { for } k=0,1, \ldots
$$

As a consequence

$$
\sum_{q=0}^{\infty}(-1)^{k} \beta_{k}(a, b)=0 .
$$

Recall that a space $X$ is called contractible if there exists a point $x_{0} \in X$ such that $I d_{X} \sim g$, where $g: X \rightarrow X$ is defined by $g(x)=x_{0}$ for every $x \in X$. 
On the other hand, let $r>0$ be small enough such that the open balls $B(\theta, r)$, $B\left(v_{i}, r\right)$, and $B\left(-v_{i}, r\right)(i=1, \ldots, m)$ are mutually disjoint. Then

$$
M_{k}(a, b)=\sum_{i=1}^{m} \operatorname{dim} C_{k}\left(J, v_{i}\right)+\sum_{i=1}^{m} \operatorname{dim} C_{k}\left(J,-v_{i}\right)+\operatorname{dim} C_{k}(J, \theta), \quad k=0,1, \ldots
$$

By Lemmas 1.5 and 1.7 , we have

$$
\begin{aligned}
\sum_{k=0}^{\infty}( & -1)^{k} M_{k}(a, b) \\
= & \sum_{i=1}^{m}\left[\sum_{k=0}^{\infty}(-1)^{k} \operatorname{dim} C_{k}\left(J, v_{i}\right)+\sum_{k=0}^{\infty}(-1)^{k} \operatorname{dim} C_{k}\left(J,-v_{i}\right)\right] \\
& \quad+\sum_{k=0}^{\infty}(-1)^{k} \operatorname{dim} C_{k}(J, \theta) \\
= & \sum_{i=1}^{m}\left[\operatorname{deg}\left(I-A, B\left(v_{i}, r\right), \theta\right)+\operatorname{deg}\left(I-A, B\left(-v_{i}, r\right), \theta\right)\right] \\
& +\operatorname{deg}(I-A, B(\theta, r), \theta) \\
= & \operatorname{deg}\left(I-A, \bigcup_{i=1}^{m}\left(B\left(v_{i}, r\right) \cup B\left(-v_{i}, r\right)\right) \cup B(\theta, r), \theta\right) \\
= & \text { an odd number. }
\end{aligned}
$$

(See the end of the proof of [11, Theorem 1.3] and [21, Theorem 1.3]). Finally, (2.15) and (2.16) imply that

$$
\sum_{k \in \mathbb{N}}(-1)^{k} \beta_{k}(a, b) \neq \sum_{k \in \mathbb{N}}(-1)^{k} M_{k}(a, b),
$$

leading to a contradiction with Lemma 1.4. As a consequence, we conclude that $J$ has an infinite number of critical points in $H_{0, p}^{1}$; therefore problem (1.1) has infinitely many weak solutions in $H_{0, p}^{1}$.

REMARK 2.14. Assumptions $\left(\mathrm{L}_{4}\right)$ and $\left(\mathrm{L}_{6}\right)$ are used to prove that the functional $J$ is well defined and the operator $A$ is compact. The proof, which is similar to that of Lemma 2.10, is omitted.

EXAMPLE 2.15. The following impulsive boundary value problem has infinitely many weak solutions in $H_{0, p}^{1}$ :

$$
\left\{\begin{array}{l}
-\left(e^{t} u^{\prime}(t)\right)^{\prime}=e^{-t} u^{5}(t), \quad t \neq t_{j}, j \in\{1,2, \ldots\}, t>0, \\
u(0)=u(+\infty)=0, \\
\Delta\left(e^{t_{j}} u^{\prime}\left(t_{j}\right)\right)=\frac{u\left(t_{j}\right)^{3}}{1+\left(t_{j}\right)^{2}}, \quad j \in\{1,2, \ldots\} .
\end{array}\right.
$$


Indeed, assumptions $\left(\mathrm{L}_{1}\right)-\left(\mathrm{L}_{6}\right)$ are satisfied:

$\left(\mathrm{L}_{1}\right) F(t, u)=u^{6} / 6=u f(t, u) / 6$ and thus $6 F(t, u) \leq u f(t, u)+6 C_{3}$, for any constant $C_{3}>0$,

( $\left.\mathrm{L}_{2}\right) F(t, u)=u^{6} / 6 \geq C_{4}|u|^{6}-C_{5}$ for $C_{4}=1 / 6$ and $C_{5}=1$,

$\left(\mathrm{L}_{3}\right) f(t, u)$ is odd,

$\left(\mathrm{L}_{4}\right)|f(t, u)| \leq g(u)$ where we may take, e.g., $g(u)=1+\left|u^{5}\right|$,

$\left(\mathrm{L}_{5}\right) I_{j}(u)=u^{3}$ is odd,

$\left(\mathrm{L}_{6}\right)$ for $\mu=5<\nu=6,5 \int_{0}^{u} I_{j}(s) d s=5 u^{4} / 4 \geq u^{4}$.

Acknowledgments. The authors are thankful to the anonymous referee for his/her careful reading of the original manuscript, which led to substantial improvements. The authors also thank their colleague A. Choutri who have used $C$ and Scilab programs to write a program computing $\lambda_{1}(R)$ in Example 2.12 (see Figure 1).

\section{REFERENCES}

[1] A. Ambrosetti and Ph. Rabinowitz, Dual variational method in critical point theory and applications, J. Funct. Anal. 14 (1973), 349-381.

[2] M. Badiale and E. Serra, Semilinear Elliptic Equations for Beginners, Universitext. Springer, London, 2011. $\mathrm{x}+199$ pp.

[3] D.D. Bainov And P.S. Simeonov, Systems with Impulse Effect. Stability, theory and applications, Ellis Horwood Series: Mathematics and its Applications. Ellis Horwood Ltd., Chichester; Halsted Press [John Wiley \& Sons, Inc.], New York, 1989, 255 pp.

[4] M. Briki, S. Djebali And T. Moussaoui, Solvability of an impulsive boundary value problem on the half-line via critical point theory, Bull. Iran. Math. Soc., to appear.

[5] K.C. Chang, Solutions of asymptotically linear operator equations via Morse theory, Comm. Pure Appl. Math. 34 (1981), no. 5, 693-712.

[6] _ Infinite Dimensional Morse Theory and Multiple Solution Problems, Progress in Nonlinear Differential Equations and their Applications, 6. Birkhäuser Boston, Inc., Boston, MA, 1993, x+312 pp.

[7] _ Methods in Nonlinear Analysis, Springer Monographs in Mathematics. SpringerVerlag, Berlin, 2005. $\mathrm{x}+439 \mathrm{pp}$.

[8] H. Chen AND J. Sun, An application of variational method to second-order impulsive differential equation on the half-line, Appl. Math. Comput. 217 (2010), no. 5, 1863-1869.

[9] K. Deimling, Nonlinear Functional Analysis, Springer-Verlag, Berlin, 1985, xiv+450 pp.

[10] D. Guo, Variational approach to a class of impulsive differential equations, Bound. Value Probl. 2014, doi:10.1186/1687-2770-2014-37, 10 pp.

[11] G. HAN AND Z. XU, Multiple solutions of some nonlinear fourth-order beam equations, Nonlinear Anal. 68 (2008), no. 12, 3646-3656.

[12] S. LiU AND S. LI, Existence of solutions for asymptotically 'linear' p-Laplacian equations, Bull. London Math. Soc. 36 (2004), no. 1, 81-87.

[13] J. Mawhin and M. Willem, Critical Point Theory and Hamiltonian Systems, Applied Mathematical Sciences, 74, Springer-Verlag, New York, 1989, xiv+277 pp.

[14] D. Motreanu, V.V. Motreanu and N. Papageorgiou, Topological and Variational Methods with Applications to Nonlinear Boundary Value Problems, Springer, New York, 2014, xii+459 pp. 
[15] J.J. Nieto AND Z. LUO, Multiple positive solutions of the singular boundary value problem for second-order impulsive differential equations on the half-line, Bound. Value Probl. 2010, Art. ID 281908, 13 pp.

[16] J.J. Nieto And D. O'Regan, Variational approach to impulsive differential equations, Nonlinear Anal. Real World Appl. 10 (2009), no. 2, 680-690.

[17] K. Perera, R. Agarwal and D. O'Regan, Morse Theoretic Aspects of p-Laplacian Type Operators, Mathematical Surveys and Monographs, 161, American Mathematical Society, Providence, RI, 2010, xx+141 pp.

[18] Ph. Rabinowitz, Variational Methods for Nonlinear Eigenvalue Problems, Eigenvalues of non-linear problems (Centro Internaz. Mat. Estivo (C.I.M.E.), III Ciclo, Varenna, 1974), pp. 139-195, Edizioni Cremonese, Rome, 1974.

[19] C. L. TANG, Multiplicity of periodic solutions for second-order systems with a small forcing term, Nonlinear Anal. Ser. A: Theory Methods 38 (1999), no. 4, 471-479.

[20] L. YAN, J. LIU AND Z. LUO, Existence and multiplicity of solutions for second-order impulsive differential equations on the half-line, Adv. Difference Equ. 2013, 2013:293, $12 \mathrm{pp}$.

[21] W. Zou And S. LI, Infinitely many solutions for Hamiltonian systems, J. Differential Equations 186 (2002), no. 1, 141-164.

Manuscript received July 25, 2014 accepted February 3, 2015

Karima Ait-Mahiout and Toufik Moussaoui

Laboratoire "Théorie du Point Fixe et Applications"

École Normale Supérieure, BP 92

Kouba, 16006, Algiers, ALGERIA

E-mail address: karima_ait@hotmail.fr, moussaoui@ens-kouba.dz

Smail Djebali

Department of Mathematics

Faculty of Sciences

IMAM University

Riyadh, SAUDI ARABIA

E-mail address: djebali@hotmail.com 